\title{
Midwives' knowledge, attitudes and confidence in discussing maternal and childhood immunisation with parents: A national study
}

\author{
Jane E Frawley ${ }^{1} \mathrm{PhD}$ \\ Kirsty McKenzie ${ }^{1} \mathrm{PhD}$ \\ Lynn Sinclair ${ }^{2} \mathrm{PhD}$ \\ Allison Cummins ${ }^{2}$ PhD \\ Jon Wardle ${ }^{3} \mathrm{PhD}$ \\ Helen Hall ${ }^{4}$ PhD
}

\footnotetext{
${ }^{1}$ Australian Centre for Public and Population Health Research, University of Technology Sydney, 235 Jones Street, Ultimo, NSW, Australia.

${ }^{2}$ Centre for Midwifery, Child and Family Health, University of Technology Sydney, 235 Jones Street, Ultimo, NSW, Australia.

${ }^{3}$ Australian Research Centre for Complementary and Integrative Medicine, University of Technology Sydney, 235 Jones Street, Ultimo, NSW, Australia.

${ }^{4}$ Monash Nursing and Midwifery, Monash University, McMahons Road, Frankston, VIC, Australia Corresponding author:

Jane E Frawley, Australian Centre for Public and Population Health Research, University of Technology Sydney, L8, Building 10, 235 Jones Street, Ultimo, NSW, Australia, 2007.

Email: jane.frawley@uts.edu.au

Phone: +61 (02) 95144808
} 


\begin{abstract}
Introduction

Despite the enormous benefits of childhood and maternal immunisation to individual and population health, the uptake of maternal vaccines during pregnancy remains suboptimal. Midwives are a trusted information source for parents and play an important role in the provision of immunisation information. Understanding midwives' attitudes and vaccine knowledge, along with their confidence to discuss maternal and childhood immunisation with parents, is key to reducing parental decisional conflict and achieving immunisation goals.
\end{abstract}

\title{
Methods
}

An online study was conducted to investigate midwives' knowledge and attitudes towards maternal and childhood vaccination along with their confidence to answer parents' vaccine-related questions. Midwives were recruited by email via the midwifery peek body, the Australian College of Midwives.

\section{Results}

A total of 359 midwives completed the online survey. The majority of midwives supported maternal (influenza $83 \%$, pertussis $90.5 \%$ ) and childhood immunisation (85.8\%); however, $69.4 \%$ of respondents wanted further training about immunisation. Midwives who felt their midwifery education adequately covered immunisation were more confident advising parents about maternal $(p=0.007)$ and childhood immunisation $(p<0.001)$. Similarly, Midwives were significantly more likely to confidently advise parents about maternal $(p<0.001)$ and childhood immunisations $(p<0.001)$ if they had completed a specific immunisation training course outside of their midwifery course.

\section{Conclusion}

Most midwives working in Australia support vaccination. However, access to contemporary, culturally appropriate education that enables midwives to engage confidently with parents about immunisation is lacking. Education based on a women-centred approach within the pre-registration curriculum along with continuing professional development programs could enable midwives to reduce the evidence to practice gap by increasing vaccine uptake.

Keywords: Midwives, vaccination, immunisation, maternal, pertussis, influenza 


\section{Introduction}

Childhood immunisation is a well-established practice in all regions of the world, while maternal immunisation is an emerging area of health care that also stands to provide significant public health impacts. Vaccine-preventable diseases such as pertussis and influenza can have drastic maternal and infant impacts if infection occurs during pregnancy or the postnatal period. The Australian Immunisation Handbook recommends an inactivated influenza vaccine for all pregnant women at any time during pregnancy and a reduced antigen diphtheria-tetanus-acellular pertussis vaccine (dTpa), in the third trimester, preferably between 20-32 weeks. ${ }^{1}$ While uptake is slowly increasing, vaccination levels remain suboptimal. ${ }^{2,3}$ The field of maternal immunisation is expected to expand with further vaccines in development that may be suitable for use during pregnancy. Examples include the respiratory syncytial virus (RSV) and Group B streptococcus vaccines, ${ }^{4,5}$ which may make this area more complex for women.

There are various models of antenatal care in Australia, with midwives participating in the majority of them (see Table 1 for an overview of models of antenatal care in Australia). ${ }^{6,7}$ Maternity care professionals, including midwives, have been identified as key professionals from whom pregnant women wish to receive information about maternal and child vaccination. ${ }^{3,11}$ Recent Australian research found one-third of mothers felt they did not receive enough information about childhood immunisation during pregnancy and only $73 \%$ of first-time mothers had made a decision about childhood vaccines during pregnancy. ${ }^{2}$ This research also highlighted that half of all participants expressed significant concern about maternal immunisation. ${ }^{2}$ Research from the UK ${ }^{12}, U^{13}$ and Australia $^{3}$ has found parents are more likely to accept a vaccine during pregnancy if a midwife recommends it. Further, research from Australia has reported that $66 \%$ of women who had expressed initial concerns about influenza vaccination would have the vaccine if it were recommended by their midwife. ${ }^{10} \mathrm{~A}$ recent systematic review of strategies to increase maternal vaccine uptake suggests that women are more likely to receive a recommended vaccine during pregnancy if it is administered by a midwife, rather than a medical practitioner. ${ }^{8}$

These results demonstrate the vital role that midwives play in both recommending vaccines and in answering women's questions about maternal and childhood immunisation. International work highlights a diversity of views on vaccination in the midwifery profession but also indicates most midwives hold positive views toward vaccination. ${ }^{12}$ For example, a UK study found most midwives supported the practice of routinely recommending the maternal influenza vaccine, ${ }^{13}$ while research from Western Australia found that $90.0 \%$ of midwives would recommend dTpa and $71.7 \%$ would recommend influenza vaccination. ${ }^{14}$ 
There were 32,669 practicing midwives in Australia at the time of this study $(27,618$ dual qualified nurse midwives and 5,051 midwives). ${ }^{15}$ The Nursing and Midwifery Board of Australia $(\mathrm{NMBA})^{16}$ expects that nurses and midwives follow the recommendations in the Australian National Immunisation Handbook. ${ }^{1}$ Furthermore, the NMBA (2016) threatens regulatory action against nurses and midwives who promote anti-vaccination sentiments. Despite such policy initiatives, ostensibly aimed at reducing perceived levels of vaccine hesitancy in the Australian midwifery profession, there is limited published work focusing on midwives' views about vaccination in the Australian context and their confidence to answer parents' questions. Much of the extant research has been conducted overseas, or within small groups, or in specific contexts in Australia (rural NSW, one tertiary hospital in Western Australia). Also, public, scientific and educational discourse about immunisation is constantly evolving, and this may impact on changing attitudes and beliefs held by health care professionals, including midwives. Rapid changes in midwifery practice and immunisation over the last ten years have given midwives a greater role in vaccination, and it is vital to know if midwives feel their education has adequately prepared them for this work environment, as well as how confident they feel advising parents about immunisation. There is a need for an up-to-date assessment of midwives' attitudes, beliefs, knowledge and confidence about immunisation, from a workforce sample of midwives throughout Australia.

\section{Methods}

\section{Study design and participants}

Semi-structured interviews with midwives $(n=23)$ were used to inform the development of an online questionnaire (Qualtrics). Themes identified from the interviews included gaps in education and training, and lacking confidence in advising parents. Midwives were recruited nationwide in MarchJuly 2018 via the midwifery professional organisation, the Australian College of Midwives (ACM). ACM directly emailed a link to the online questionnaire with the participant information sheet to members of the College. A follow-up reminder email was sent four weeks later. ACM also included information about the study in their newsletter that is emailed to all members monthly. Ethics approval was gained from the University of XXXXXX (ETH17-1602).

\section{Materials}

The online questionnaire included forty-two items that explored midwifery education, immunisation training, workforce issues related to immunisation, and parental vaccine concerns, alongside 
attitudes, information-seeking practices and midwives' level of confidence discussing childhood and maternal vaccines with parents. ACM sent unique invitation emails to all members ( $n=2,677)$.

Participant demographics, education and workplace characteristics

Midwives were asked if they were a registered midwife in Australia and what environments they worked in (public hospital, private hospital, birth centre, private practice (endorsed midwife), doctor's surgery, community health centre, other, not currently practising). Midwives were asked their age (18-24, 25-34, 35-44, 45-54, 55-64, 65 and over), level of education (undergraduate certificate, undergraduate diploma, bachelor degree, post-graduate certificate, post-graduate diploma, master's degree coursework, master's degree research, PhD), whether they were also registered as a nurse in Australia (yes/no), whether they believed their immunisation training was adequate within their midwifery training (not adequate, somewhat adequate, highly adequate), and whether they had participated in an immunisation training course (yes/no). Participants were asked which state and/or territory they worked in and whether this area is urban, rural, or outer rural/remote. Length of time in clinical midwifery practice was determined as $<2$ years, 3-5 years, 6-10 years, $>10$ years.

\section{Midwife attitudes toward vaccination}

Midwives were asked how important they thought influenza and pertussis containing vaccinations were for pregnant women (very important, moderately important, neither important or unimportant, moderately unimportant, very unimportant). Further Likert scales using five-point measures from "strongly disagree" to "strongly agree" rated midwives' attitudes and beliefs about maternal and childhood vaccines and immunisation. Items covered issues such as the perceived value of maternal and childhood vaccines (e.g. vaccines are important for children; maternal vaccines are important for pregnant women), perceived vaccine safety (e.g. vaccines contain ingredients that can cause harm, vaccines can cause autism, vaccines can cause allergies) and perceived vaccine efficacy (e.g. there are better ways to protect children than vaccines).

\section{Providing information and immunisation services}

Midwives were asked if giving vaccines to pregnant women was a routine part of their role (yes, no). The questionnaire asked midwives how often parents expressed concerns about maternal and childhood vaccines (never, occasionally, frequently) and how confident they felt answering these questions (not confident at all, somewhat confident, highly confident). Midwives were also asked what resources they recommended to parents who wanted additional information (I don't, I feel they need to do their own research, general practitioner, paediatrician, complementary medicine practitioner, certain Internet sites, Department of Health literature that is available on immunisation, 
I don't, I am not sure where to refer them to get unbiased information, other), and if they would like additional training in immunisation (no, my training was adequate, no it's not something I am interested in, no I don't get asked for information by parents, yes I have a few questions about immunisation, yes I don't have much understanding about immunisation).

\section{Data Analysis}

Raw data were extracted in an electronic spreadsheet and imported into statistical analysis software. Frequencies and proportions were calculated to describe sample demographics, work characteristics and environment, immunisation training, vaccine information sources, confidence addressing parental concerns, and attitudes toward maternal and childhood vaccination. Chi-square tests were conducted to assess relationships between time spent in practice (up to 5 years, 6 to 10 years, over 10 years) and self-reported adequacy of immunisation education; and desire for further immunisation education (yes/no). A further Chi-square was conducted to explore if having done a specific immunisation training course was related to perceived adequacy of immunisation education. Cramer's V was used to determine effect size. Analyses were conducted using IBM SPSS ${ }^{\circledR}$ software.

\section{Results}

\section{Demographics}

Three-hundred and fifty-nine midwives completed the questionnaire in full (response rate of 13.4\%). Nearly all the participants were female $(n=357)$, in line with the gender profile of the profession. ${ }^{16}$ The age group frequencies of participants were $18-24$ years (2.8\%), 25-34 years (10.6\%), 35-44 years $(15.6 \%), 45-54$ years $(29.2 \%), 55-64$ years $(37 \%)$, and 65 years and over $(4.7 \%)$, in line with the age profile of the profession. ${ }^{16}$ The majority of the participants had been in practice for over ten years (68.8\%) and worked in public hospitals in urban centres (capital cities or other major cities) (64.3\%). Table 2 shows the practice characteristics for the group.

\section{Midwifery education and immunisation training}

While some midwives were hospital trained (common before the 1990's), the majority of participants had a degree $(20.6 \%)$ or post-graduate degree $(62.4 \%)$ qualification, and $32.3 \%$ had completed an immunisation training course. The majority of participants felt their midwifery education had not adequately covered immunisation, with more than $50 \%$ of participants indicating that it was not adequate at all (53.5\%) and a further $41.8 \%$ indicating that it was only somewhat 
adequate. The majority of participants (69.4\%) indicated that they would like additional training on immunisation.

Length of time in midwifery practice was significantly associated with further education on immunisation. Midwives who had been in practice for over 10 years were more likely to have completed a specific immunisation training course $(p<0.001$, Cramer's $V=0.235)$ Midwives who completed a specific immunisation training course were more likely to believe that their immunisation training within their midwifery program was deficient $(p=0.007$; Cramer's $V=0.143$ ) (data not shown). Midwives who had been in practice for up to five years were more likely to want additional immunisation training ( $p=0.029$, Cramer's V $=0.154$ ) (Table 3).

\section{Advising parents}

The majority of midwives believed influenza vaccination during pregnancy was very important (59.6\%) or moderately important (23.4\%). Similarly, $71.0 \%$ believed pertussis-containing vaccine was very important and $19.5 \%$ believed it was moderately important during pregnancy. When asked about childhood vaccines, $69.6 \%$ of midwives strongly agreed, and $16.2 \%$ agreed that they are important. A total of $83.3 \%$ of midwives indicated that giving maternal vaccines was part of their role, while $86.1 \%$ gave childhood immunisations. Our results indicated that advising parents about immunisation was part of the midwifery role and that many midwives were asked for advice about maternal vaccination $(44.3 \%)$ and childhood vaccination (43.7\%) frequently (Table 4$)$. In addition, the vast majority of participants indicated that parents expressed concerns about maternal or childhood vaccines, occasionally $(79.9 \%)$ or frequently $(13.6 \%)$ (Table 4$)$.

The vast majority of participants expressed some level of confidence in providing advice to parents about maternal and childhood immunisation. However, only $40.7 \%$ felt highly confident to advise about maternal immunisation, and only $42.1 \%$ felt highly confident to advise about childhood immunisation (Table 5). When further information about vaccination was needed, midwives referred parents to Department of Health literature on immunisation (85.8\%), GPs (45.7\%), paediatricians (14.8\%), certain Internet sites (13.4\%) and complementary medicine practitioners (0.8\%). Internet sites that midwives recommended primarily included government sites such as Immunise Australia. Five per cent of midwives indicated that they did not refer parents as they were not sure where to get unbiased information and $2.5 \%$ answered that they don't refer as parents need to do their own research. 
Two chi-square tests were conducted to explore relationships between education and confidence to advise parents (Table 5). Midwives who felt their midwifery education adequately covered immunisation were significantly more likely feel confident advising parents about maternal immunisation ( $p=0.007$, Cramer's V $=0.140)$ and childhood immunisation $(p<0.001$, Cramer's V = 0.168). Midwives were significantly more likely to confidently advise parents about maternal ( $p<$ 0.001 , Cramer's V $=0.410)$ and childhood immunisations $(p<0.001$, Cramer's $V=0.420)$ if they had completed a specific immunisation training course (Table 5).

\section{Beliefs and attitudes towards immunisation}

The majority of midwives (54.9\%) had no concerns about immunisation, $34.3 \%$ had minor concerns, while $10 \%$ had a lot of concerns and $0.8 \%$ indicated that they did not believe in immunisation. Participants were also asked about their specific beliefs about immunisation including the importance of maternal and childhood vaccines; the seriousness of the illnesses for which childhood vaccines are given; and beliefs about autism and allergies (Table 6).

\section{Discussion}

Immunisation has become a routine aspect of midwifery care, and significant changes have occurred in recent years, including the introduction of $\mathrm{dTpa}$ and influenza vaccines during pregnancy. This study was conducted to provide an up-to-date account of midwives' attitudes, beliefs and knowledge about immunisation, along with their education needs and confidence to answer parents' questions about maternal and childhood vaccination.

The majority of midwives in our study agreed that vaccines are important for pregnant women. This finding concurs with a recent study from a tertiary maternity hospital in Western Australia that found midwives displayed broad support for maternal vaccines, with $90 \%$ stating they would recommend dTpa vaccine for pregnant women, and $71.7 \%$ would recommend the influenza vaccine for pregnant women. ${ }^{14}$ Results from our study are also in line with a recent Australian study of maternity care professionals, including 129 midwives that found $83 \%$ would recommend dTpa during pregnancy and $78 \%$ would recommend the influenza vaccine. ${ }^{17}$ Our study found the vast majority of midwives also believed childhood immunisations were important which corresponds with a recent systematic review that found broad support for infant and childhood immunisation, despite reservations among a minority of midwives. ${ }^{12}$ 
Our results suggest large deficits in midwifery-focused immunisation education with more than half of all midwives surveyed reporting their education about immunisation was inadequate, and over two-thirds are wanting access to further training in maternal and childhood immunisation. Importantly, no significant relationship was found between length of time in practice and adequacy of education, suggesting that even graduates who have recently entered clinical midwifery practice, after the introduction of maternal vaccination, felt their training did not adequately prepare them to take an active role in vaccination discussion. In addition, our research found midwives who had not completed an immunisation training course lacked confidence in discussing immunisation with parents. This finding is in line with previous research that explored factors related to vaccine recommendation by maternity care professionals, finding confidence in vaccine knowledge integral to endorsing maternal vaccines. ${ }^{17}$

Despite contemporary health policy and health care delivery models providing midwives with a more significant role in immunisation, universal changes in midwifery immunisation education have not accompanied this changing role. In Australia, current midwifery curriculum requirements include 'education concerning immunisation' ${ }^{18}$ but no further detail is provided. An appropriate level of education may therefore be ad hoc or adopted only in some contexts or states. Recent Australian research that found very few hours dedicated to immunisation training within midwifery programs. ${ }^{19}$ Our study suggests the need for further research into the integration of immunisation training into contemporary educational contexts in Australia, as current educational approaches may not adequately prepare midwives for this aspect of their role. ${ }^{19}$ Other recent Australian research also supports this contention, finding almost all surveyed midwives wanted more education on some aspect of maternal immunisation including information about evidence for maternal influenza vaccine (80.7\%) and dTpa vaccine (81.9\%); information on implications for the foetus/newborn (78.3\%); and information on the roles and expectations of health care professionals regarding maternal immunisation (74.3\%). ${ }^{14}$ Our research indicates that this issue is not restricted to the maternal context and may reflect a need for additional education in both maternal and childhood immunisation. Additionally, education and training on how to have effective conversations with parents about immunisation may also be required to encourage trust and confidence and increase vaccine uptake.

Our study also provides an up-to-date account of midwives' attitudes and beliefs about maternal and childhood immunisation in Australia. While only a minimal number of midwives in our study agreed with the comment that vaccines cause autism (3.4\%), nearly $14 \%$ neither agreed nor disagreed, suggesting some midwives may withhold judgement about this issue. This represents an improvement from earlier research conducted in Australia, ${ }^{20}$ which found $40 \%$ of midwives were unsure if there was an association between the MMR vaccine and autism. While this theory has been 
thoroughly discredited ${ }^{21}$ and fewer midwives appear to be vaccine-hesitant as a result, our study shows that some midwives may still be uncertain. Similarly, one-third of midwives in our study either believed that vaccines caused allergies, or were not sufficiently confident that vaccines did not cause allergies. This uncertainty, may in part, be why some midwives find it difficult to answer parent's questions related to vaccine safety. This uncertainty may also be related to midwives' lack of uniform education in immunisation, including vaccine safety and efficacy, and their desire for further information and ongoing education.

The present study has several limitations. Study participants were more likely to be older midwives who had spent a long time in practice which may mean the results are more reflective of the beliefs and attitudes of this group. Study participants were recruited through the Australian College of Midwives which represents around $8 \%$ of the profession, and it is impossible to know if members are representative of the broader profession of midwives in Australia. The college has been more vocal about its pro-immunisation stance in recent years which may be a disincentive for potential members with dissenting views. Additionally, the response rate was low and therefore these results are not reflective of all midwives in Australia. Responder bias may have also impacted the results of this study due to the politicised nature of the topic. Despite these limitations, this is the first Australian study that has attempted to represent midwives from every state and territory, across all work environments, to better characterise vaccination knowledge, information needs and attitudes.

In conclusion, the results of this national study indicate broad support for maternal and childhood vaccination among Australian midwives. However, midwifery education on this critical topic is currently inadequate. In order to develop the knowledge and confidence to engage in explicit communication, midwives need access to up-to-date, culturally appropriate education on vaccines, immunisation and effective communication. This education must be based on a woman-centred approach, which acknowledges the ability of women to make their own informed choices. Offerings should include continuing professional education and the integration of relevant material in the preregistration curriculum. Vaccination is an essential public health initiative and with appropriate education, midwives are ideally placed to support parents who have questions about maternal and childhood vaccines. 


\section{Acknowledgements and Disclosures}

We are grateful to the National Health and Medical Research Council (NHMRC) for an Early Career Fellowship (GNT1124075) that supported Dr Jane Frawley during this research. We would also like to acknowledge Professor Cathrine Fowler for her help in designing this study.

The authors have no conflicts of interest to disclose. 
Table 1: The major models of antenatal care in Australia ${ }^{6,7}$

\begin{tabular}{|l|l|}
\hline Private maternity care & $\begin{array}{l}\text { Antenatal care provided by a private specialist obstetrician or a general } \\
\text { practitioner (GP) obstetrician. Antenatal care may also be provided by } \\
\text { an obstetrician and midwife from the same private practice. }\end{array}$ \\
\hline $\begin{array}{l}\text { Public hospital } \\
\text { maternity care }\end{array}$ & $\begin{array}{l}\text { Antenatal care is provided in a hospital outpatient clinic by midwives. } \\
\text { Care could also be provided by a multidisciplinary team. In the case of } \\
\text { high-risk or complex pregnancies, care is provided by specialist } \\
\text { obstetricians and/or maternal-foetal medicine specialists. }\end{array}$ \\
\hline Shared care & $\begin{array}{l}\text { A formal arrangement for antenatal care between a local practitioner } \\
\text { in the community (GP, midwife) and a public hospital. The local } \\
\text { practitioner provides the majority of the care with the woman usually } \\
\text { visiting the hospital at designated times in her pregnancy (usually at } \\
\text { booking 12-16 weeks, 28-32 weeks and toward the end of her } \\
\text { pregnancy). }\end{array}$ \\
\hline Team midwifery care & $\begin{array}{l}\text { Antenatal care is provided by a team of rostered midwives who } \\
\text { collaborate with an obstetrician as per the Australian College of } \\
\text { Midwives guidelines for consultation and referral. }\end{array}$ \\
\hline $\begin{array}{l}\text { Midwifery group } \\
\text { practice (MGP) or } \\
\text { caseload midwifery }\end{array}$ & $\begin{array}{l}\text { MGP and caseload are midwifery-led continuity of care models. } \\
\text { Women will receive care from a known midwife or small group of } \\
\text { midwives (2-4) throughout pregnancy, birth and in the early parenting } \\
\text { period. The midwives work in collaboration with obstetricians as per } \\
\text { the Australian College of Midwives guidelines for consultation and } \\
\text { referral. }\end{array}$ \\
\hline private midwifery care & $\begin{array}{l}\text { Privately practising midwives offer continuity of care, providing care to } \\
\text { women from early in their pregnancy, through birth and into the first } \\
\text { few weeks after the birth mostly in the woman's home. }\end{array}$ \\
\hline $\begin{array}{l}\text { Some privately practising midwives and some public hospitals offer } \\
\text { midwifery led care only in antenatal and postnatal period. The woman } \\
\text { will give birth at the public hospital with the core midwifery staff who } \\
\text { work in the birth unit. }\end{array}$ \\
\hline
\end{tabular}


Table 2: Practice characteristics

\begin{tabular}{|c|c|c|c|}
\hline Time in practice & & Highest midwifery qualification & \\
\hline Up to 5 years & $80(22.3 \%)$ & Undergraduate certificate & $52(14.5 \%)$ \\
\hline 6 to 10 years & 32 (8.9\%) & Undergraduate diploma & $9(2.5 \%)$ \\
\hline \multirow[t]{2}{*}{ Over ten years } & $247(68.8 \%)$ & Degree & $74(20.6 \%)$ \\
\hline & & Post-graduate certificate & $60(16.7 \%)$ \\
\hline Current work Location & & Post-graduate diploma & $94(26.2 \%)$ \\
\hline Urban (major city) & $231(64.3 \%)$ & Master's degree (coursework) & $55(15.3 \%)$ \\
\hline Rural & $103(28.7 \%)$ & Master's degree (research) & $11(3.1 \%)$ \\
\hline Outer rural/remote & $21(5.8 \%)$ & $\mathrm{PhD}$ & $4(1.1 \%)$ \\
\hline Not currently practising & $4(1.1 \%)$ & & \\
\hline & & Current work environment & \\
\hline State practised in* & & Public hospital & $260(72.4 \%)$ \\
\hline ACT & $15(4.2 \%)$ & Private hospital & $18(5.0 \%)$ \\
\hline New South Wales & $131(36.5 \%)$ & Birth centre & $13(3.6 \%)$ \\
\hline Northern Territory & $13(3.6 \%)$ & Private practice (endorsed midwife) & $8(2.2 \%)$ \\
\hline Queensland & $87(24.2 \%)$ & Private practice (eligible midwife) & $1(0.3 \%)$ \\
\hline South Australia & $22(6.1 \%)$ & Doctor's surgery & $4(1.1 \%)$ \\
\hline Tasmania & $5(1.4 \%)$ & Community health centre & $17(4.7 \%)$ \\
\hline Western Australia & $34(9.5 \%)$ & Other & $34(9.5 \%)$ \\
\hline Victoria & $64(17.8 \%)$ & Not currently practising & $4(1.1 \%)$ \\
\hline
\end{tabular}

*more than $100 \%$ as participants could select more than one state 
Table 3: Immunisation training and length of time in midwifery practice

\begin{tabular}{|c|c|c|c|}
\hline & \multicolumn{3}{|c|}{ Time spent in midwifery practice } \\
\hline & $\begin{array}{l}\text { Up to } 5 \text { years } \\
n=80(22.3 \%)\end{array}$ & $\begin{array}{l}6-10 \text { years } \\
n=32(8.9 \%)\end{array}$ & $\begin{array}{l}\text { Over } 10 \text { years } \\
n=247(68.8 \%)\end{array}$ \\
\hline \multicolumn{4}{|l|}{$\begin{array}{l}\text { Level of immunisation training in midwifery } \\
\text { qualification }\end{array}$} \\
\hline \multirow{2}{*}{$\begin{array}{r}\text { Highly adequate, } 17(4.7 \%) \\
\text { Somewhat adequate, } 150(41.8 \%)\end{array}$} & $4(5.0 \%)$ & $0(0.0 \%)$ & $13(5.3 \%)$ \\
\hline & $41(51.3 \%)$ & $13(40.6 \%)$ & $96(38.9 \%)$ \\
\hline Not adequate, 192 (53.5\%) & $35(43.8 \%)$ & $19(59.4 \%)$ & $138(55.9 \%)$ \\
\hline \multicolumn{4}{|l|}{$\begin{array}{l}\text { Would you like additional training in } \\
\text { immunisation? }\end{array}$} \\
\hline \multirow{2}{*}{$\begin{array}{r}\text { Yes, } 249(69.4 \%) \\
\text { No, } 110(30.6 \%)\end{array}$} & $64(80 \%)$ & $24(75 \%)$ & $161(65.2 \%)$ \\
\hline & $16(20 \%)$ & $8(35 \%)$ & $86(34.8 \%)$ \\
\hline
\end{tabular}

Table 4: Provision of advice about immunisation

\begin{tabular}{|r|c|c|c|}
\hline & Never & Occasionally & Frequently \\
\hline Asked for advice about childhood vaccination & $16(4.5 \%)$ & $186(51.8 \%)$ & $157(43.7 \%)$ \\
\hline Asked for advice about maternal vaccination & $18(5.0 \%)$ & $182(50.7 \%)$ & $159(44.3 \%)$ \\
\hline Parents express concerns & $23(6.4 \%)$ & $287(79.9 \%)$ & $49(13.6 \%)$ \\
\hline
\end{tabular}


Table 5: Midwives' confidence in providing advice to parents

\begin{tabular}{|c|c|c|c|c|c|c|}
\hline & \multicolumn{3}{|c|}{$\begin{array}{l}\text { How confident do you feel advising parents about } \\
\text { maternal vaccines? }\end{array}$} & \multicolumn{3}{|c|}{$\begin{array}{l}\text { How confident do you feel advising pal } \\
\text { about childhood vaccines? }\end{array}$} \\
\hline & $\begin{array}{l}\text { Highly confident } \\
146(40.7 \%)\end{array}$ & $\begin{array}{l}\text { Somewhat } \\
\text { confident } \\
198(55.2 \%)\end{array}$ & $\begin{array}{c}\text { Not } \\
\text { confident } \\
15(4.2 \%)\end{array}$ & $\begin{array}{c}\text { Highly } \\
\text { confident } \\
151(42.1 \%)\end{array}$ & $\begin{array}{l}\text { Somewhat } \\
\text { confident } \\
180(50.1 \%)\end{array}$ & $\begin{array}{r}N \\
\text { confi } \\
28(\bar{T}\end{array}$ \\
\hline \multicolumn{7}{|l|}{ Level of immunisation training in midwifery qualification ${ }^{\text {a, } b}$} \\
\hline Highly adequate, 17 (4.7\%) & $13(8.9 \%)$ & $4(2.0 \%)$ & $0(0.0 \%)$ & $12(7.9 \%)$ & $4(2.2 \%)$ & $1(3$. \\
\hline Somewhat adequate, 150 (41.8\%) & $56(38.4 \%)$ & $91(46.0 \%)$ & $3(20.0 \%)$ & $60(39.7 \%)$ & $87(48.3 \%)$ & $3(1 \mathrm{C}$ \\
\hline Not adequate, 192 (53.5\%) & $77(52.7 \%)$ & $103(52.0 \%)$ & $12(80.0 \%)$ & $79(52.3 \%)$ & $89(49.4 \%)$ & $24(8$ \\
\hline \multicolumn{7}{|l|}{ Participation in a specific immunisation training course ${ }^{c, d}$} \\
\hline Yes, $116(32.3 \%)$ & $80(54.8 \%)$ & $35(17.7 \%)$ & $1(6.7 \%)$ & $83(55.0 \%)$ & $32(17.8 \%)$ & $1(3$ \\
\hline No, $243(67.7 \%)$ & $66(45.2 \%)$ & $16382.3 \%)$ & $14(93.3 \%)$ & $68(45.0 \%)$ & $148(82.2 \%)$ & $27(9$ \\
\hline
\end{tabular}


Table 6: Midwives' beliefs about maternal and childhood vaccines

\begin{tabular}{|c|c|c|c|c|c|}
\hline & $\begin{array}{l}\text { Strongly } \\
\text { disagree }\end{array}$ & Disagree & Neutral & Agree & $\begin{array}{c}\text { Strongly } \\
\text { agree }\end{array}$ \\
\hline $\begin{array}{r}\text { Maternal vaccines are important for } \\
\text { pregnant women }\end{array}$ & $\begin{array}{c}29 \\
(8.1 \%)\end{array}$ & $\begin{array}{c}12 \\
(3.3 \%)\end{array}$ & $\begin{array}{c}38 \\
(10.6 \%)\end{array}$ & $\begin{array}{c}89 \\
(24.8 \%)\end{array}$ & $\begin{array}{c}191 \\
(53.2 \%)\end{array}$ \\
\hline Vaccines are important for children & $\begin{array}{c}19 \\
(5.3 \%)\end{array}$ & $\begin{array}{c}7 \\
(1.9 \%)\end{array}$ & $\begin{array}{c}25 \\
(7.0 \%)\end{array}$ & $\begin{array}{c}58 \\
(16.2 \%)\end{array}$ & $\begin{array}{c}250 \\
(69.6 \%)\end{array}$ \\
\hline $\begin{array}{l}\text { Vaccines are given to children to } \\
\text { prevent illness that are not serious }\end{array}$ & $\begin{array}{c}225 \\
(62.7 \%)\end{array}$ & $\begin{array}{c}92 \\
(25.6 \%)\end{array}$ & $\begin{array}{c}23 \\
(6.4 \%)\end{array}$ & $\begin{array}{c}14 \\
(3.9 \%)\end{array}$ & $\begin{array}{c}5 \\
(1.4 \%)\end{array}$ \\
\hline $\begin{array}{r}\text { Children should get natural immunity } \\
\text { from diseases }\end{array}$ & $\begin{array}{c}196 \\
(54.6 \%)\end{array}$ & $\begin{array}{c}96 \\
(26.7 \%)\end{array}$ & $\begin{array}{c}47 \\
(13.1 \%)\end{array}$ & $\begin{array}{c}16 \\
(4.5 \%)\end{array}$ & $\begin{array}{c}2 \\
(1.1 \%)\end{array}$ \\
\hline Vaccines can cause autism & $\begin{array}{c}241 \\
(67.1 \%)\end{array}$ & $\begin{array}{c}57 \\
(15.9 \%)\end{array}$ & $\begin{array}{c}50 \\
(13.9 \%)\end{array}$ & $\begin{array}{c}9 \\
(2.5 \%)\end{array}$ & $\begin{array}{c}2 \\
(0.6 \%)\end{array}$ \\
\hline Vaccines can cause allergies & $\begin{array}{c}164 \\
(45.7 \%)\end{array}$ & $\begin{array}{c}79 \\
(22.0 \%)\end{array}$ & $\begin{array}{c}86 \\
(24 \%)\end{array}$ & $\begin{array}{c}25 \\
(7.0 \%)\end{array}$ & $\begin{array}{c}5 \\
(1.4 \%)\end{array}$ \\
\hline $\begin{array}{r}\text { There are better ways to protect } \\
\text { children than vaccines }\end{array}$ & $\begin{array}{c}207 \\
(57.7 \%)\end{array}$ & $\begin{array}{c}90 \\
(25.1 \%)\end{array}$ & $\begin{array}{c}42 \\
(11.7 \%)\end{array}$ & $\begin{array}{c}13 \\
(3.6 \%)\end{array}$ & $\begin{array}{c}7 \\
(1.9 \%)\end{array}$ \\
\hline $\begin{array}{r}\text { Children get too many vaccines during } \\
\text { the first two years of life }\end{array}$ & $\begin{array}{c}139 \\
(38.7 \%)\end{array}$ & $\begin{array}{c}95 \\
(26.5 \%)\end{array}$ & $\begin{array}{c}55 \\
(15.3 \%)\end{array}$ & $\begin{array}{c}38 \\
(10.6 \%)\end{array}$ & $\begin{array}{c}32 \\
(8.9 \%)\end{array}$ \\
\hline $\begin{array}{r}\text { Vaccines contain ingredients that can } \\
\text { cause harm }\end{array}$ & $\begin{array}{c}127 \\
(35.4 \%)\end{array}$ & $\begin{array}{c}92 \\
(25.6 \%)\end{array}$ & $\begin{array}{c}85 \\
(23.7 \%)\end{array}$ & $\begin{array}{c}42 \\
(11.7 \%)\end{array}$ & $\begin{array}{c}13 \\
(3.6)\end{array}$ \\
\hline $\begin{array}{r}\text { Serious side-effects from vaccines are } \\
\text { too common for me to accept }\end{array}$ & $\begin{array}{c}221 \\
(61.6 \%)\end{array}$ & $\begin{array}{c}83 \\
(23.1 \%)\end{array}$ & $\begin{array}{c}35 \\
(9.7 \%)\end{array}$ & $\begin{array}{c}13 \\
(3.6 \%)\end{array}$ & $\begin{array}{c}7 \\
(1.9 \%)\end{array}$ \\
\hline
\end{tabular}


References

1. Australian Technical Advisory Group on Immunisation. Australian Immunisation Handbook, Australian Government Department of Health, Canberra, immunisationhandbook.health.gov.au. 2018.

2. Danchin MH, Costa-Pinto J, Attwell K, et al. Vaccine decision-making begins in pregnancy: Correlation between vaccine concerns, intentions and maternal vaccination with subsequent childhood vaccine uptake. Vaccine 2018; 36(44): 6473-9.

3. McCarthy EA, Pollock WE, Tapper L, Sommerville M, McDonald S. Increasing uptake of influenza vaccine by pregnant women post H1N1 pandemic: a longitudinal study in Melbourne, Australia, 2010 to 2014. BMC Pregnancy Childbirth 2015; 15: 53.

4. Higgins D, Trujillo C, Keech C. Advances in RSV vaccine research and development - A global agenda. Vaccine 2016; 34(26): 2870-5.

5. Vekemans J, Moorthy V, Friede M, et al. Maternal immunization against Group B streptococcus: World Health Organization research and development technological roadmap and preferred product characteristics. Vaccine 2018.

6. Donnolley N, Butler-Henderson K, Chapman M, Sullivan E. The development of a classification system for maternity models of care. Health Information Management Journal 2016; 45(2): 6470.

7. Australian Government Department of Health. 2009. Improving Maternity Services in Australia; The report of the maternity services review. Available from:

https://www1.health.gov.au/internet/publications/publishing.nsf/Content/msr-report ${ }^{\sim}$ ssreport-tables $\sim$ msr-report-table2

8. Bisset KA, Paterson P. Strategies for increasing uptake of vaccination in pregnancy in highincome countries: A systematic review. Vaccine 2018; 36(20): 2751-9.

9. Regan AK, Mak DB, Hauck YL, Gibbs R, Tracey L, Effler PV. Trends in seasonal influenza vaccine uptake during pregnancy in Western Australia: Implications for midwives. Women Birth 2016; 29(5): 423-9.

10. Wiley KE, Massey PD, Cooper SC, Wood N, Quinn HE, Leask J. Pregnant women's intention to take up a post-partum pertussis vaccine, and their willingness to take up the vaccine while pregnant: a cross sectional survey. Vaccine 2013; 31(37): 3972-8.

11. Wiley KE, Massey PD, Cooper SC, et al. Uptake of influenza vaccine by pregnant women: a crosssectional survey. Med J Aust 2013; 198(7): 373-5.

12. Maisa A, Milligan S, Quinn A, et al. Vaccination against pertussis and influenza in pregnancy: a qualitative study of barriers and facilitators. Public Health 2018; 162: 111-7.

13. Ogburn T, Espey EL, Contreras V, Arroyo P. Impact of clinic interventions on the rate of influenza vaccination in pregnant women. J Reprod Med 2007; 52(9): 753-6.

14. Attwell K, Wiley KE, Waddington C, Leask J, Snelling T. Midwives' attitudes, beliefs and concerns about childhood vaccination: A review of the global literature. Vaccine 2018; 36(44): 6531-9.

15. Ishola DA, Jr., Permalloo N, Cordery RJ, Anderson SR. Midwives' influenza vaccine uptake and their views on vaccination of pregnant women. J Public Health (Oxf) 2013; 35(4): 570-7.

16. Regan AK, Hauck Y, Nicolaou L, et al. Midwives' knowledge, attitudes and learning needs regarding antenatal vaccination. Midwifery 2018; 62: 199-204.

17. Nursing and Midwifery Board of Australia. Reporting preriod: 1 April 2018 - 30 June 2018. Available from: https://www.nursingmidwiferyboard.gov.au/About/Statistics.aspx

18. Australian Institute of Health and Welfare. Nursing and midwifery workforce 2015 , available from: https://www.aihw.gov.au/reports/workforce/nursing-and-midwifery-workforce2015/contents/who-are-nurses-and-midwives 2015. 
19. Krishnaswamy S, Wallace EM, Buttery J, Giles ML. A study comparing the practice of Australian maternity care providers in relation to maternal immunisation. Aust N Z J Obstet Gynaecol 2018.

20. Australian Nursing and Midwifery Accreditation Council 2014, Midwives Standards and Criteria for the Accreditation of Nursing and Midwifery Courses Leading to Registration, Enrolment, Endorsement and Authorisation in Australia, Australian Nursing and Midwifery Council, viewed 18th July 2014, http://www.anmac.org.au/midwife-accreditation-standards-2014

21. Attwell K, Yusuf A, Frawley J. Is immunisation education in midwifery degrees adequate? Hum Vaccin Immunother 2018: 1-4.

22. Leask J, Quinn HE, Macartney K, et al. Immunisation attitudes, knowledge and practices of health professionals in regional NSW. Aust N Z J Public Health 2008; 32(3): 224-9.

23. Taylor LE, Swerdfeger AL, Eslick GD. Vaccines are not associated with autism: an evidence-based meta-analysis of case-control and cohort studies. Vaccine 2014; 32(29): 3623-9. 